\title{
Rare Case of Takayasu's Arteritis Associated with Crohn's Disease
}

\author{
Ryusaku Kusunoki ${ }^{1}$, Shunji Ishihara ${ }^{1}$, Mariko Sato ${ }^{3}$, Yoshiko Sumita ${ }^{3}$, Yoshiyuki Mishima ${ }^{1}$, \\ Mayumi Okada ${ }^{1}$, Yasumasa Tada ${ }^{1}$, Akihiko Oka ${ }^{1}$, Nobuhiko Fukuba ${ }^{1}$, Naoki Oshima ${ }^{1}$, \\ Ichiro Moriyama ${ }^{1}$, Takafumi Yuki ${ }^{2}$, Shuichi Sato', Yuji Amano ${ }^{2}$, \\ Yohko Murakawa ${ }^{3}$ and Yoshikazu Kinoshita ${ }^{1}$
}

\begin{abstract}
Takayasu's arteritis (TA) and Crohn's disease (CD) are chronic inflammatory diseases of uncertain etiology. Although co-existence of these rare diseases is estimated to occur in 1 in 10 billion individuals, a theoretically unexpected association has been reported in several patients and it is suggested that those associations may have been more than an unusual coincidence. Herein, we report a case of TA associated with clinically inactive CD. A Japanese woman was diagnosed with colonic CD at the age of 15, developed aortic valve regurgitation at 19 , and then presented with general fatigue, low grade fever, and painful sensations in her left arm at 25. She was diagnosed with TA based on computed tomography scanning and magnetic resonance angiography findings, and treatments with prednisolone and cyclosporine were started. Thereafter, valve replacement and right coronary artery bypass graft surgery were performed. The possible pathophysiological mechanism responsible for concurrent existence of TA and CD may be associated with immune disorders. Early diagnosis of vascular lesions for patients with inflammatory bowel disease is highly encouraged.
\end{abstract}

Key words: Crohn's disease, Takayasu's arteritis

(Intern Med 50: 1581-1585, 2011)

(DOI: 10.2169/internalmedicine.50.5406)

\section{Introduction}

Crohn's disease (CD) is often associated with extraintestinal complications and is manifested in various organs such as the skin, eyes, joints, and cardiovascular system. Takayasu's arteritis (TA), also known as pulseless disease, is an autoimmune-mediated disorder that develops into chronic vasculitis, which mainly involves the aorta and its branches, though it has an uncertain etiology. Several case reports have noted TA and CD in the same patient, though such coexistence has been theoretically estimated to occur in only 1 in 10 billion individuals (1-28). Thus, there may be a pathophysiological link between these diseases. Herein, we report a rare case of TA associated with clinically inactive CD.

\section{Case Report}

A 15-year-old Japanese female first came to our hospital in 1998 complaining of low grade fever and upper abdominal pain. Colonic CD was diagnosed by colonoscopy findings, which showed patchy and longitudinal mucosal ulcerations, cobblestone areas, and strictures in the transverse colon (Fig. 1). Barium enema X-ray results indicated no extension of the disease into the small intestine. Fecal culture results showed normal bacterial microflora. Although a colonic histological examination revealed marked infiltration of inflammatory cells, non-caseating epithelioid cell granulomas were not observed. The diagnosis of CD in this patient was based on typical endoscopic findings, as noted above. Physical examinations, including blood pressure, pulse, and

${ }^{1}$ Department of Internal Medicine II, Shimane University School of Medicine, Japan, ${ }^{2}$ Division of Endoscopy, Shimane University Hospital, Japan and ${ }^{3}$ Department of Rheumatology, Shimane University Hospital, Japan

Received for publication February 25, 2011; Accepted for publication March 29, 2011

Correspondence to Dr. Shunji Ishihara, si360405@med.shimane-u.ac.jp 

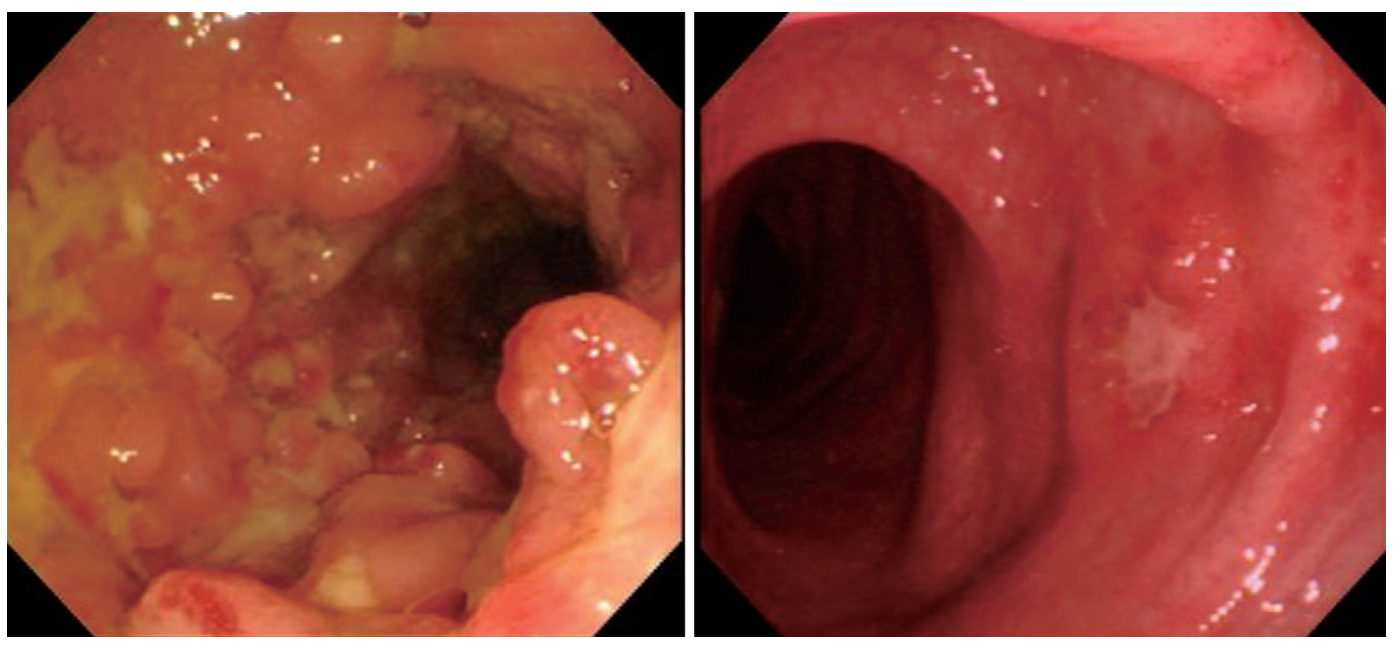

Figure 1. Colonoscopy image showing characteristic findings of CD, including patchy and longitudinal ulcerations with pseudopolyps and stenosis.

heart sounds, were normal at the onset of CD. Over the next 10 years, her abdominal symptoms were well controlled by treatment with mesalazine. However, she intermittently complained of general fatigue, low grade fever, arthralgia, and headache, though no specific CD symptoms were noted. In 2002, the patient underwent surgery for arthritis in the bilateral wrists and aortic valve regurgitation was incidentally discovered.

In 2008 , at the age of 25 years old, the patient reported general malaise, recurrent fever, and a sense of numbness in the left arm during exercise. In a physical examination, a systolic ejection murmur was heard along the left upper sternal border, and the left humeral and radial pulses were markedly diminished. Blood pressure in the right upper limb was $92 / 70 \mathrm{mmHg}$, while it was $70 / 50 \mathrm{mmHg}$ on the left side. Bruits were audible over the bilateral carotid arteries. On the other hand, her abdomen was flat and soft, with no tenderness to palpation. Laboratory test results at that time showed an erythrocyte sedimentation rate (ESR) of $131 \mathrm{~mm} /$ hour, white blood cell count at $6,980 / \mu \mathrm{L}$, red blood cell count at 3.8 million $/ \mu \mathrm{L}$, hemoglobin at $9.2 \mathrm{~g} / \mathrm{dL}$, hematocrit at $29.4 \%$, platelet count of $460,000 / \mu \mathrm{L}$, total protein at 7.9 $\mathrm{g} / \mathrm{dL}$, albumin at $3.1 \mathrm{~g} / \mathrm{dL}$, and C-reactive protein (CRP) at $8.4 \mathrm{mg} / \mathrm{dL}$. A colonoscopy examination revealed only a few superficial aphthous lesions in the proximal colon. Although computed tomography (CT) scanning did not show any intestinal inflammation or abdominal abscesses, thickening of the wall of the aorta was detected, while magnetic resonance angiography (MRA) also revealed thickness of the aortic wall and periaortic soft tissues from the aortic arch to thoracic aorta. The vascular branches of the aorta were stenotic, with the left subclavian artery markedly narrowed. Echocardiography showed a dilated left ventricle and severe aortic incompetence. Results of cardiac catheterization and coronary angiography also confirmed severe aortic regurgitation and marked narrowing of the right coronary ostium (Fig. 2).

Based on these findings, the patient was diagnosed with $\mathrm{TA}$ and treatments with aspirin $(100 \mathrm{mg} /$ day $)$, warfarin $(3.5$ $\mathrm{mg} /$ day), and prednisolone $(60 \mathrm{mg} /$ day $)$ were started. Her symptoms improved substantially, with decreases in CRP and ESR. However, when prednisolone was reduced to 20 $\mathrm{mg} /$ day, inflammatory levels took a turn for the worse and $150 \mathrm{mg}$ of cyclosporine was added, which resulted in gradual improvements in laboratory data. After the inflammation had subsided, the patient underwent aortic valve replacement and right coronary artery bypass graft surgery for severe aortic regurgitation and stenosis of the coronary artery, which were performed without complications. At the time of writing, she is doing well and continuing treatment with prednisolone, cyclosporine, aspirin, and warfarin.

\section{Discussion}

$\mathrm{CD}$ is a chronic inflammatory disorder of the gastrointestinal tract, with onset typically occurring in the second and third decades of life, and the majority of affected individuals progressing to relapsing and chronic disease. According to large epidemiological studies, CD is most common in Scandinavia, Great Britain, and North America, with lower rates reported in southern Europe, Africa, and Asia. The incidence and prevalence of CD could be as high as 14.6/100,000 per year and 199/100,000, respectively (29).

In 1905, Takayasu described a 21-year old woman with a peculiar arteriovenous malformation of the optic fundus (30), while Onishi (31) and Kagoshima (32) described similar ocular findings along with absence of radial pulse in the same year. Thereafter in 1951, the clinical features of TA were summarized by Shimizu and Sano in an English language journal under the name "pulseless disease (33)." TA is known to be a type of chronic vasculitis mainly involving the aorta and its main branches, with adolescent girls and women in their second and third decades of life at higher risk. TA is rare and it is most commonly reported in Japan, Southeast Asia, India, and Mexico. In 1990, the Japanese government added TA to the list of intractable diseases, with 5,000 patients included in the list over the subsequent 

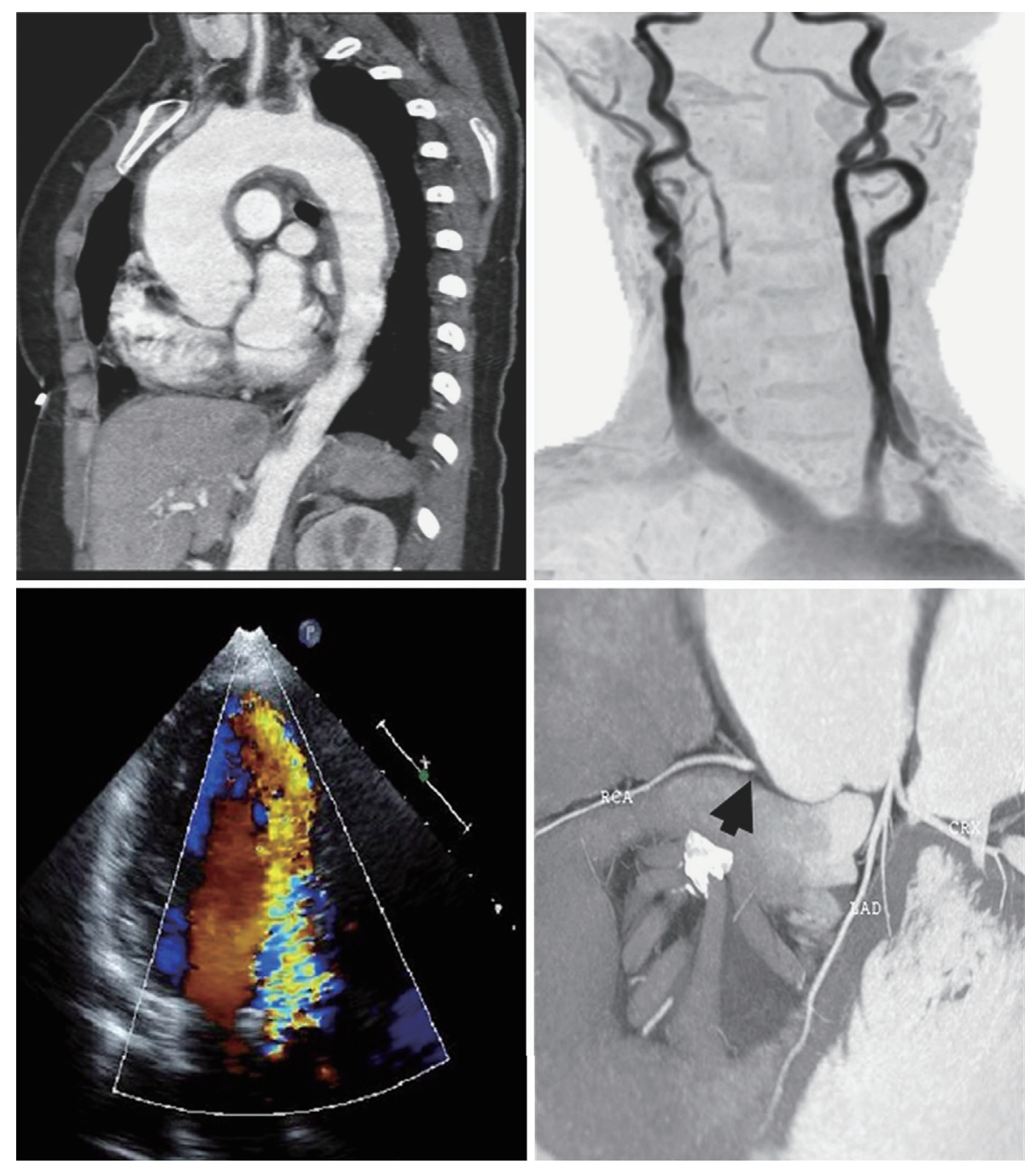

\begin{tabular}{l|l}
$\mathbf{A}$ & $\mathbf{B}$ \\
\hline $\mathbf{C}$ & $\mathbf{D}$
\end{tabular}

Figure 2. (A) CT scan showing thickening of the aorta wall. (B) MRA image revealing stenotic vascular branches of the aorta, with the left subclavian artery markedly narrowed. (C) Echocardiography image showing a dilated left ventricle and severe aortic regurgitation. (D) CT coronary angiography image revealing serious narrowing of the right coronary ostium.

decade. On the other hand, a study of North American patients found the incidence to be 2.6/1 million/year (7), though the true extent of the disease in western countries is not known.

TA and CD are both rare diseases, and the chance of their co-existence has been estimated to be 1 in 10 billion individuals (1). On the other hand, theoretically unexpected associations have been reported by several authors, with the first case of TA associated with CD described by Yassinger et al (1). In a North American study of 32 TA patients, 2 also had CD (7). Kerr et al found that 2 of 64 TA patients had CD and 2 other cases had ulcerative colitis (UC) (10). In addition, Reny et al reported that $\mathrm{CD}$ was present in $9 \%$ of a group of 44 TA patients (14). In Table 1, including the present case, we have listed 37 cases of $\mathrm{CD}$ and TA in the same individual, reported in literature (1-28). For those 37 patients, the age at diagnosis was noted for 32 cases, of whom the onset of TA symptoms was simultaneous or later that that of $\mathrm{CD}$ in $78 \%(25 / 32)$ of the affected patients, suggesting that $\mathrm{CD}$ may be a trigger of TA, though it is diffi- cult to accurately determine its onset. The activities of both diseases were reported in 14 and occurred in parallel in $43 \%$ (6/14) of those cases. The present patient had followed a good course for controlling $\mathrm{CD}$, even though her drug compliance was poor.

Four cases of surgery for $\mathrm{CD}$ have been reported among patients with co-existing TA. However, the long term prognosis of each disease in patients with both is unknown. Reny et al reported that patients with coexistent TA and CD tended to be younger at the time of diagnosis, and also tended to have systemic symptoms more frequently than those with TA alone. On the other hand, the distribution of vascular lesions in patients with both diseases does not seem to be different from that of patients with TA alone (14). No evidence of a genetic link between TA and CD has been reported, while UC, another major form of IBD, has been reported to be complicated with TA in some cases, with the HLA-B52 and -DR2 antigens known to have common associations with UC and TA (35).

Early diagnosis and treatment are very important for pa- 
Table 1. 37 Case Reports of Takayasu's Arteritis Associated with Crohn's Disease

\begin{tabular}{|c|c|c|c|c|c|c|c|c|c|c|}
\hline \multirow[b]{2}{*}{ No } & \multirow[b]{2}{*}{ Auther } & \multirow[b]{2}{*}{ Year } & \multirow[b]{2}{*}{ Sex } & \multicolumn{2}{|c|}{ Age at diag. } & \multicolumn{2}{|c|}{ Type } & \multirow[b]{2}{*}{ Activity } & \multirow[b]{2}{*}{ Therapy } & \multirow[b]{2}{*}{ Reference } \\
\hline & & & & $\mathrm{CD}$ & $\mathrm{TA}$ & $\mathrm{CD}$ & $\mathrm{TA}$ & & & \\
\hline 1 & Yassinger & 1976 & $\mathrm{~F}$ & 12 & 15 & NA & $\mathrm{V}$ & NA & PSL & 1 \\
\hline 2 & Reimund & 1977 & $\mathrm{~F}$ & 21 & 33 & NA & NA & NA & NA & 2 \\
\hline 3 & Friedman & 1979 & $\mathrm{~F}$ & 24 & 21 & IC & NA & $\mathrm{CD}>\mathrm{TA}$ & PSL, Sulfasalazine, TA ope & 3 \\
\hline 4 & Owyang & 1979 & $\mathrm{~F}$ & 15 & 19 & $\mathrm{C}$ & NA & $\mathrm{CD}=\mathrm{TA}$ & PSL & 4 \\
\hline 5 & Beau & 1980 & $\mathrm{~F}$ & 17 & 17 & NA & $\mathrm{V}$ & NA & NA & 5 \\
\hline 6 & Lenhoff & 1982 & $\mathrm{~F}$ & 24 & 24 & $\mathrm{C}$ & $\mathrm{V}$ & $\mathrm{CD}=\mathrm{TA}$ & PSL & 6 \\
\hline 7 & Hall & 1985 & NA & NA & NA & NA & NA & NA & NA & 7 \\
\hline 8 & & & NA & NA & NA & NA & NA & NA & NA & \\
\hline 9 & Elburg & 1992 & $\mathrm{~F}$ & 14 & 14 & $\mathrm{C}$ & $\mathrm{V}$ & $\mathrm{CD}=\mathrm{TA}$ & PSL & 8 \\
\hline 10 & Bentineb & 1992 & $\mathrm{~F}$ & 31 & 23 & NA & NA & NA & NA & 9 \\
\hline 11 & Kerr & 1994 & NA & NA & NA & NA & NA & NA & NA & 10 \\
\hline 12 & & & NA & NA & NA & NA & NA & NA & NA & \\
\hline 13 & Houman & 1995 & $\mathrm{M}$ & 19 & 19 & NA & I & NA & NA & 11 \\
\hline 14 & Hilario & 1998 & M & 10 & 14 & I & $\mathrm{IIb}$ & $\mathrm{CD}<\mathrm{TA}$ & PSL, AZA, Sulfasalazine & 12 \\
\hline 15 & Todini & 1999 & $\mathrm{~F}$ & 10 & 23 & NA & NA & NA & NA & 13 \\
\hline 16 & & & $\mathrm{~F}$ & 22 & 24 & NA & NA & NA & NA & \\
\hline 17 & Reny & 2000 & $\mathrm{~F}$ & 16 & 20 & NA & I & NA & PSL & 14 \\
\hline 18 & & & $\mathrm{~F}$ & 23 & 34 & NA & I & NA & PSL & \\
\hline 19 & & & $\mathrm{~F}$ & 30 & 20 & NA & I & NA & PSL, CD ope & \\
\hline 20 & & & $\mathrm{~F}$ & 24 & 26 & NA & $\mathrm{V}$ & NA & PSL & \\
\hline 21 & Goldman & 2000 & M & 13 & 33 & NA & NA & NA & PSL, MTX, TA ope & 15 \\
\hline 22 & Biagi & 2001 & $\mathrm{~F}$ & 15 & 22 & $\mathrm{C}$ & $\mathrm{V}$ & $\mathrm{CD}<\mathrm{TA}$ & PSL, Mesalazine & 16 \\
\hline 23 & & & $\mathrm{~F}$ & 39 & 35 & IC & I & $\mathrm{CD}=\mathrm{TA}$ & PSL, Mesalazine, CD ope & \\
\hline 24 & Levitsky & 2002 & $\mathrm{~F}$ & 12 & 20 & NA & $\mathrm{V}$ & NA & PSL & 17 \\
\hline 25 & Ohta & 2003 & $\mathrm{~F}$ & 20 & 16 & NA & III & NA & PSL & 18 \\
\hline 26 & Kettaneh & 2003 & $\mathrm{~F}$ & 16 & 16 & NA & NA & NA & PSL, AZA, CD ope & 19 \\
\hline 27 & & & $\mathrm{~F}$ & 29 & 29 & NA & NA & NA & PSL & \\
\hline 28 & Ozsoyler & 2005 & M & 34 & 40 & NA & NA & $\mathrm{CD}<\mathrm{TA}$ & Anticoagulation, TA ope & 20 \\
\hline 29 & Domenech & 2005 & $\mathrm{~F}$ & 20 & 27 & IC & NA & $\mathrm{CD}=\mathrm{TA}$ & PSL, Infliximab, G-CAP, CD ope & 21 \\
\hline 30 & Cheema & 2005 & $\mathrm{~F}$ & 28 & 45 & NA & NA & $\mathrm{CD}<\mathrm{TA}$ & TA ope & 22 \\
\hline 31 & Dumarey & 2007 & $\mathrm{~F}$ & 18 & 18 & NA & NA & $\mathrm{CD}<\mathrm{TA}$ & PSL & 23 \\
\hline 32 & Baqir & 2007 & $\mathrm{~F}$ & $<20$ & 20 & NA & IV & NA & NA & 24 \\
\hline 33 & Burke & 2008 & NA & NA & NA & NA & NA & NA & NA & 25 \\
\hline 34 & Kellermayer & 2008 & $\mathrm{~F}$ & 12 & 17 & $\mathrm{C}$ & $\mathrm{V}$ & $\mathrm{CD}=\mathrm{TA}$ & PSL, Mesalamine, 6-MP, Infliximab & 26 \\
\hline 35 & Farrant & 2008 & $\mathrm{~F}$ & 25 & 24 & I & I & $\mathrm{CD}>\mathrm{TA}$ & $\mathrm{CD}$ ope & 27 \\
\hline 36 & Liu & 2009 & M & 18 & 17 & IC & I & NA & PSL & 28 \\
\hline 37 & This case & 2010 & $\mathrm{~F}$ & 15 & 25 & $\mathrm{C}$ & $\mathrm{IIb}$ & $\mathrm{CD}<\mathrm{TA}$ & PSL, Cyclosporine, TA ope & \\
\hline
\end{tabular}

NA: not available, I: illeum, C: colon, PSL: plednisolone, AZA: azatioprine,

MTX: methotrexate, G-CAP: granulocyteapheresis, 6-MP: 6-mercaptopurine

tients with TA to prevent renal hypertension, aortic regurgitation, congestive heart failure, and cerebrovascular accident. A delay between symptoms and diagnosis ranging from 2 to 11 years has been reported in western countries (36). On the other hand, a study in India reported delays of only 2.5 to 5.5 months (37). This discrepancy likely reflects the difference in disease incidence between the two populations, which results in different levels of awareness (34). The present patient was found to have TA 6 years after being diagnosed with aortic regurgitation. Since her CD symptoms were well controlled and she did not complain of other symptoms, it was difficult to make an early diagnosis of TA.

When there is a discrepancy between clinical inflamma- tory markers and gastrointestinal symptoms in IBD patients, attention should be paid to extraintestinal complications including TA. Physical examinations, including measuring of bilateral blood pressure and pulses, and detection of systolic heart sound murmur, are important for early diagnosis of TA. A recent study suggested that non-invasive modalities including ultrasonography (US), CT, MRI, and fluoro-Dglucose-positron emission tomography (FDG-PET) can provide a diagnosis of TA early in the course of the disease (38). When such modalities are used for patients with IBD based on their symptoms, careful evaluation of the results for diagnosis of cardiovascular diseases including TA is important. 
The authors state that they have no Conflict of Interest (COI).

\section{References}

1. Yassinger S, Adleman R, Cantor D, Halsted CH, Bolt RJ. Association of inflammatory bowel disease and large vascular lesions. Gastroenterology 71: 844-846, 1976.

2. Reimund JM, Duclos B, Mechine A, et al. Granulomatous involvement of the pancreas in Crohn disease associated with Takayasu arteritis. Gastroenterol Clin Biol 21: 437-438, 1997 (in French).

3. Friedman CJ, Tegtmeyer CJ. Crohn's disease associated with Takayasu's arteritis. Dig Dis Sci 24: 954-958, 1979.

4. Owyang C, Miller LJ, Lie JT, Fleming CR. Takayasu's arteritis in Crohn's disease. Gastroenterology 76: 825-828, 1979.

5. Beau B, Colasse W, Le Bihan G, Bourreille J. Association of Takayasu's arteritis and inflammatory bowel disease. Sem Hop Paris 56: 1841-1845, 1980 (in French).

6. Lenhoff SJ, Mee AS. Crohn's disease of the colon with Takayasu's arteritis. Postgrad Med J 58: 386-389, 1982.

7. Hall S, Barr W, Lie JT, Stanson AW, Kazmier FJ, Hunder GG. Takayasu's arteritis. A study of 32 North American patients. Medicine 64: 88-99, 1985.

8. Van Elburg RM, Henar EL, Bijleveld CM, Prins TR, Heymans HS. Vascular compromise prior to intestinal manifestation of Crohn's disease in a 14-year-old girl. J Pediatr Gastroenterol Nutr 14: 97-100, 1992.

9. Ben Zineb N, Zine S, Bellasfar M, Mesaad MJ, Sfar R. A propos de l'assocoation arterite de Takayasu, maladie de Crohn et prossesse. Rev Fr Gynecol Obest 87: 591-593, 1992.

10. Kerr GS, Hallahan CW, Giordano J, et al. Takayasu arteritis. Ann Intern Med 120: 919-929, 1994.

11. Houman MH, Doghri A, Boubaker J, et al. Maladie de Takayasu au cours d'une maladie de Crohn: une association exeptionnelle. Ann Gastroenterol Hepatol 31: 337-340, 1996.

12. Hilario MO, Terreri MT, Prismich G, et al. Asssociation of ankylosing spondylitis, Crohn's disease and Takayasu's arteritis in a child. Clin Exp Rheumatol 16: 92-94, 1998.

13. Todini AR, Heinzmann MM, Antignani PL, Paiella ML. Association between Takayasu's arteritis and Crohn's disease in two young women: case reports. J Mal Vasc 24: 373-376, 1999.

14. Reny JL, Paul JF, Lefèbvre C, et al. Association of Takayasu's arteritis and Crohn's disease. Results of astudy on 44 Takayasu patients and review of the literature. Ann Med Interne (Paris) 154: 85-90, 2003.

15. Goldman MH, Akl B, Mafi S, Pastore L. Granulomatous aortitis presenting as an acute myocardial infarction in Crohn's disease. Circulation 102: 3023-3024, 2000.

16. Biagi P, Castro R, Campanella G, Parisi G, Gobbini AR, Vedovini G. Takayasu's arteritis and Crohn's disease - an unusual association. Report on two cases. Digest Liver Dis 33: 487-491, 2001.

17. Levitsky J, Harrison JR, Cohen RD. Crohn's disease and Takayasu's arteritis. J Clin Gastroenterol 34: 454-456, 2002.

18. Ohta Y, Ohya Y, Fujii K, et al. Inflammatory diseases associated with Takayasu's disease. Angiology 54: 339-344, 2003.
19. Kettaneh A, Prevot S, Biaggi A. Hypertyroidism in two patients with Crohn's disease and Takayasu's arteritis. Scand J Gastroenterol 8: 901-903, 2003.

20. Ozsoyler I, Yilik L, Bozok S, Ozbek C, Gurbuz A. Cardiovascular involvement in Crohn's disease in the absence of ankylosing spondylitis. Heart Vessels 20: 164-166, 2005.

21. Domènech E, Garcia-Planella E, Olazábal A, et al. Abdominal aortitis associated with Crohn's disease. Dig Dis Sc 50: 11221123, 2005.

22. Cheema AA, Mcneil AJ. Left main coronary artery stenosis associated with aortitis in a patient with Crohn's disease. Heart 92: 618, 2006.

23. Dumarey N, Tang BN, Goldman S, et al. Papillary muscle inflammation in Takayasu's arteritis revealed by FDG-PET. Eur Heart $\mathbf{J}$ 28: 1011, 2007.

24. Baqir M, Usman MHU, Adenwalla HN. Takayasu's arteritis with skin manifestations in a patient with inflammatory bowel disease: coincidence or concurrence? Clin Reumatol 26: 996-998, 2007.

25. Burke AP, Tavora F, Narula N, Tomaszewski JE, Virmani R. Aortitis aortic aneurism: description of 52 cases and proposal of a histologic classification. Human Pathology 39: 514-526, 2008.

26. Kellermayer R, Jain AK, Ferry G, Deguzman MM, Guillerman RP. Clinical challenges and images in GI. Aortitis as a rare complication of Crohn's disease. Gastroenterology 134: 668-669, 2008.

27. Farrant M, Mason JC, Wong N, Longman RJ. Takayasu's arteritis following Crohn's disease in a young woman: Any evidence for a common pathogenesis? World J Gastroenterol 14: 4087-4090, 2008.

28. Liu Y, Fang Y, Ruan L, Li YM, Li L, Jiang LL. Takayasu's arteritis associated with Crohn's disease. J Zhejiang Univ Sci B 10: 631-634, 2009.

29. Rerenstein CN, Blanchard JF. The epidemiology of Crohn's disease. Gastroenterology 116: 1503-1504, 1999.

30. Takayasu M. A case with peculiar changes of the retinal central vessels. Acta Soc Opth Jpn 12: 554-555, 1908 (in Japanese).

31. Onishi K. Discussion on Takayasu's presentation. Acta Soc Opth Jpn 12: 555, 1908 (in Japanease).

32. Kagoshima S. Discussion on Takayasu's presentation. Acta Soc Opth Jpn 12: 555, 1908 (in Japanease).

33. Shimizu K, Sano K. Pulseless disease. J Neuropathl Clin Neurol 1: $37-47,1951$.

34. Johnston SL, Lock RJ, Gompels MM. Takayasu arteritis: a review. J Clin Pathol 55: 481-486, 2002.

35. Morita Y, Yamamura M, Suwaki K, et al. Takayasu's arteritis associated with ulcerative colitis; genetic factors in this association. Intern Med 35: 574-578, 1996.

36. Lupi-Herrera E, Sanchez-Torres G, Marcushamer J, Mispireta J, Horwitz S, Vela JE. Takayasu arteritis. Clinical study of 107 cases. Am Heart J 93: 94-103, 1997.

37. Jain S, Sharma N, Singh S, Bali HK, Kumar L, Sharma BK. Takayasu arteritis in children and young Indians. Int J Cardiol 75: S153-S157, 2000.

38. Andrews J, Mason JC. Takayasu's arteritis-recent advances in imaging offer promise. Reumatology 46: 6-15, 2007.

(C) 2011 The Japanese Society of Internal Medicine

http://www.naika.or.jp/imindex.html 